\title{
EL PATRIMONIO Y EL TERRITORIO COMO ACTIVOS PARA EL DESARROLLO DESDE LA PERSPECTIVA DEL OCIO Y DEL TURISMO ${ }^{1}$
}

\author{
Rocío Silva Pérez \\ Víctor Fernández Salinas \\ Departamento de Geografía Humana \\ Universidad de Sevilla
}

\section{RESUMEN}

Este artículo parte de una concepción compleja y multidimensional del desarrollo y de los recursos utilizables para su consecución y tiene en cuenta la creciente importancia conferida al turismo cultural en las dinámicas socio-económicas y territoriales. Con tales presupuestos plantea una propuesta metodológica que ayude a profundizar en el análisis de la forma en que los distintos ámbitos utilizan los recursos disponibles, y se centra en aquellos relacionados con la práctica de un turismo cultural respetuoso y sostenible, a la par que generador de rentas y empleo.

El trabajo se estructura en dos grandes apartados correspondientes a otras tantas fases analíticas: a) Una fase inicial de identificación de los recursos territoriales y patrimoniales disponibles en cada ámbito (estructura físico-territorial y patrimonio natural y cultural) y b) una segunda fase centrada en las posibilidades de conversión de tales recursos en productos turísticos merced, tanto a la disponibilidad de infraestructuras existentes, como a la visibilidad de las infraestructuras y los recursos. A modo de epílogo, se señalan algunos ejemplos de determinación de la calidad que pueden ser considerados estrategias innovadoras para avanzar en el logro de una actividad turística respetuosa e integrada en el entorno y satisfacer al mismo tiempo las demandas ciudadanas emergentes.

Palabras clave: Turismo cultural, territorio, patrimonio, desarrollo.

\section{ABSTRACT}

From a complex and multidimensional developmente conception and the avalaible resources for its aims, and considering the increasing socioeconomic dynamic importance

1 Este artículo se integra en los Proyectos de I+D del Ministerio de Educación y Ciencia SEJ2006-15331C02-01 y SEJ 2006-14277-C04-03. Así mismo, algunos contenidos del mismo se relacionan con el Proyecto de Investigación de Excelencia de la Junta de Andalucía P06-SEJ-01714. 
conferred to the cultural tourism in the territory, this methodologic proposes to progress in the analysis of the way in which the different scopes use the resources available, being centered in those related to the practice of a respectful and sustainable cultural tourism, on a par that generating of rents and use. The work structure in two great sections corresponding to other so many methodologic phases: a) An initial phase of identification of the territorial and patrimonial resources available in each scope (physical-territorial structure and natural and cultural patrimony) and b) one second phase centered in the conversion possibilities of such tourist product resources favor, as much to the existing infrastructure availability, like a the visibility of infrastructures and the resources. As a epilogue, some examples of determination of the quality are indicated that can be considered strategies innovating to advance in the profit of a tourist activity respectful and integrated in the surroundings and to satisfy the emergent citizen demands at the same time.

Key words: Cultural turism, territory, heritage, development.

\section{Planteamientos básicos}

El nuevo contexto socioeconómico y territorial surgido a partir de los procesos de reestructuración inducidos por la globalización durante los últimos decenios se ha visto acompañado de una alteración no menos significativa del entendimiento del desarrollo y de los recursos utilizables para su consecución. De la inicial identificación de desarrollo con crecimiento evaluable, sobre todo, a partir de indicadores económicos convencionales preferentemente aplicables a pequeñas escalas (PIB, renta per cápita, disponibilidad de determinados servicios y equipamientos como líneas de telefonía, oficinas bancarias, automóviles...), se ha pasado a una consideración compleja del desarrollo que integra tres dimensiones básicas: económica, ambiental y social (Jiménez Herrero, 1982; AA.VV., 2006, Caravaca Barroso, González Romero, Silva Pérez, 2005). Su aplicabilidad, además, se circunscribe preferentemente a grandes y medianas escalas, más próximas al concepto de región y comarca, en las que las relaciones sociales y culturales cobran un creciente protagonismo llegando a condicionar la propia dinámica económica.

Paralelamente a todo ello ha tenido lugar una ampliación del concepto y de los recursos utilizables para el desarrollo. En un primer momento, los procesos de desarrollo se asociaban a la combinación de tres tipos de recursos: la presencia de materias primas y fuentes de energía — capital natural—, la disponibilidad de medios técnicos y financieros para explotar tales recursos — capital productivo- y la existencia de infraestructuras y equipamientos adecuados para el desenvolvimiento de la actividad productiva — capital físico-territorial- (Silva y Moral, 2005). Con posterioridad (decenio de los setenta del siglo pasado), el agotamiento de los recursos naturales y el progresivo deterioro ambiental obligó a replantear la forma de relacionar economía y medio ambiente, revisándose buena parte de la terminología científico-económica e incorporándose nuevas categorías conceptuales como la de desarrollo sostenible (Brundtland y otros, 1989). A partir de los años ochenta se revaloriza el capital humano, evaluado a partir del nivel formativo de la población al que algunos autores consideran como «el principal activo de cualquier economía» (Jiménez Latorre y Rams Ramos, 2002, 51). A finales de estos años ochenta e inicios de los noventa empieza a generalizarse la tesis de que los procesos de desarrollo están estrechamente enraizados en la estructura social; se acuña así el concepto de capital social entendido como la capacidad de concertación socio-institucional de las sociedades y los territorios, que está en gran medida condicionada por la existencia de lazos culturales comunes (Moyano, 2001). Ello remite a otra categoría conceptual, la de de capital cultural, que hace referencia «a 
la capacidad adaptativa de las poblaciones humanas que les permite enfrentarse al entorno natural y modificarlo» (Bordieu, 1997). Más recientemente se ha llegado a considerar que el propio territorio constituye, en sí mismo, un recurso cultural y económico de primer orden, lo que remite a un nuevo concepto, el de patrimonio territorial (Ortega Valcárcel, 1998), que hace referencia tanto a su disposición físico-natural como a los recursos patrimoniales disponibles en cada ámbito, incluidos aquellos de carácter intangible que refuerzan la identidad y confieren una mayor competitividad a los territorios.

Una andadura, en suma, que culmina con una concepción compleja y multidimensional de lo que se entiende por desarrollo y de los recursos utilizables para su consecución (CEPAL, 1991). Ello exige la utilización imaginativa de nuevos indicadores para su medición y caracterización, en su mayoría de carácter cualitativo, cuya identificación y operatividad territorial está en gran parte de los casos pendiente de precisar, matizar y analizar. Es importante tener en cuenta, en estrecha relación con lo anterior, que para llevar a cabo este tipo de análisis las estadísticas habitualmente disponibles no son suficientes, lo que requiere indagar nuevas fuentes estadísticas y acudir a las técnicas cualitativas de investigación y al trabajo de campo a través de la realización de entrevistas y encuestas a instituciones y agentes sociales con presencia activa en cada ámbito. Todo ello se acompaña de una creciente revalorización del papel del territorio en los procesos de desarrollo y de una apuesta por la identidad como activo para su logro. Como ha señalado Vázquez Barquero (2005, 15) «la respuesta local al aumento de la competencia pasa por la formulación y ejecución de estrategias de desarrollo territorial, instrumentadas a través de acciones que persigan el aumento de la eficiencia, la mejora de la distribución de la renta y el mantenimiento de los recursos naturales y del patrimonio histórico y cultural». A su vez, de la concepción del territorio como simple soporte estático de recursos genéricos, se ha pasado a su entendimiento como generador de recursos específicos que resultan estratégicos para impulsar la competitividad en un mundo cada vez más globalizado.

En este nuevo contexto de relaciones dialécticas entre las escalas global y local, una de las principales contradicciones a que deben hacer frente las sociedades actuales es la pugna creciente entre las tendencias globalizadoras y la revitalización experimentada por las identidades locales depositarias de recursos patrimoniales, únicos e irrepetibles, que resultan cruciales para propiciar el desarrollo en un mundo cada vez más competitivo y homogéneo. En estrecha relación con todo ello, son cada vez más abundantes las propuestas de desarrollo amparadas en la utilización con fines turísticos de los recursos específicos e irrepetibles de cada ámbito. A esto no es ajeno el hecho de un aumento y reconceptualización del ocio de las clases acomodadas y medias de todo el mundo, que son mucho más propicias a moverse y a consumir la oferta turística de territorios, tanto lejanos como cercanos, y en cuyo proceso inciden aspectos tan distintos como el abaratamiento de los medios de transporte, el reconocimiento social que otorga el conocimiento de países y culturas distintas, las modas relacionadas con algunos deportes (asistencia a eventos deportivos, golf...) y un largo etcétera que mueve a los territorios a procurar potenciar políticas que los hagan atractivos. La manera de consumir el tiempo de ocio se ha convertido pues en una forma de evaluar la calidad de vida en la medida que se utiliza para incrementar el conocimiento y el espíritu crítico. Conocer otras culturas, admirar nuevos paisajes, visitar monumentos, pero también degustar y adquirir productos de lugares en los que experimentar sensaciones nuevas e intensas, se ha convertido en una de las aspiraciones que contribuyen a que un individuo se sienta más satisfecho.

En este discurso, puede apreciarse un cambio notable desde el punto de vista del consumidor de turismo cultural. Frente al turista de los años sesenta y setenta que valoraba sobre todo el exotismo y no experimentaba escrúpulos ante situaciones de pobreza, atraso económico y/o 
situaciones de dictadura política, el turista cultural actual valora progresivamente que la puesta en valor de los recursos culturales se realice en contextos de equilibrio y justicia social, respeto medioambiental y, además, con una oferta cultural asociada a los recursos patrimoniales que complete el producto ofrecido por un territorio (Romero Moragas, 2001).

Por todo ello, y volviendo a un discurso más general, las distintas dimensiones del desarrollo (ambiental, económica, social) y su necesaria complementariedad han llevado a reparar en la importancia que adquiere la forma de utilizar y poner en valor los recursos propios. Mientras su utilización racional ayuda a potenciar los procesos de desarrollo, su desaprovechamiento se convierte en una rémora para la activación económica, al tiempo que su mal uso redunda en disfunciones ambientales, culturales, sociales y territoriales que coartan la competitividad.

Pese a la reiterada insistencia de los discursos teóricos en la necesidad de activar todos los recursos disponibles y la creciente atención dispensada a los recursos territoriales y patrimoniales, que por su carácter único e irrepetible acrecientan la competitividad territorial, no se ha avanzado aún suficientemente en la elaboración de propuestas metodológicas que ayuden a sistematizar tales propuestas y mucho menos a evaluarlas (Fernández Salinas, 2003).

El objetivo de este estudio es avanzar en unan propuesta metodológica que ayude a profundizar en la forma en que los distintos ámbitos utilizan sus recursos, comprobando si ésta es la idónea para propiciar procesos de desarrollo o si, por el contrario, éstos son utilizados de manera inadecuada o se mantienen ociosos. Entre los recursos susceptibles de ser activados (monetarios, humanos, territoriales, ambientales...), este trabajo se centra en la consideración del patrimonio territorial desde una doble perspectiva: a) el análisis de la estructura físico-territorial que, aparte de constituir un recurso básico para el desarrollo, permite la utilización de los restantes recursos disponibles y contribuye, además, a la generación de las sinergias interterritoriales imprescindibles para la utilización racional, equilibrada y complementaria de tales recursos; y b) el patrimonio con que cuenta el territorio, considerando como tal a todo recurso territorial que genera y refuerza la identidad (Fernández Salinas, 2003), por lo que tiene la virtualidad - cuando se utiliza adecuadamente- de activar la especificidad de cada ámbito e incrementar su competitividad. A su vez, aunque se parte de una concepción compleja y multidimensional del desarrollo que no desdeña las facetas social y ambiental a él asociadas, se pone el acento en la dimensión económica y, más específicamente, en la utilización del patrimonio territorial por actividades relacionadas con el ocio y el turismo. La selección de este ámbito de reflexión no es casual; además de las razones ya expuestas sobre la tendencia a convertir los territorios en escenarios turísticos como modo de desarrollo en la sociedad del ocio, el cambio social y funcional de muchas comarcas rurales en Europa y España, aboca al turismo casi como única vía de salida para conjurar el marasmo económico y el colapso demográfico, especialmente en zonas de montaña, de difícil acceso o con problemas para generar procesos de desarrollo. Se revela pues de interés primordial para los territorios valorar, ponderar y conocer la capacidad de acogida de los recursos susceptibles de ser movilizados para los procesos de desarrollo, sobre todo para aquellos relacionados con el turismo cultural.

La propuesta metodología planteada consta a tal fin de dos fases (figura 1):

1) Una fase inicial de identificación de los recursos territoriales y patrimoniales disponibles en cada ámbito.

2) Una segunda fase centrada en las posibilidades de conversión de tales recursos en productos turísticos merced, tanto a la disponibilidad de infraestructuras existentes, como a la visibilidad de las infraestructuras y los recursos. 
A modo de epílogo, se señalan algunos ejemplos de determinación de la calidad (tanto de las infraestructuras como de los recursos y los productos) que pueden ser consideradas como estrategias innovadoras para avanzar en el logro de una actividad turística respetuosa e integrada en el entorno y satisfacer al mismo tiempo las demandas ciudadanas emergentes.

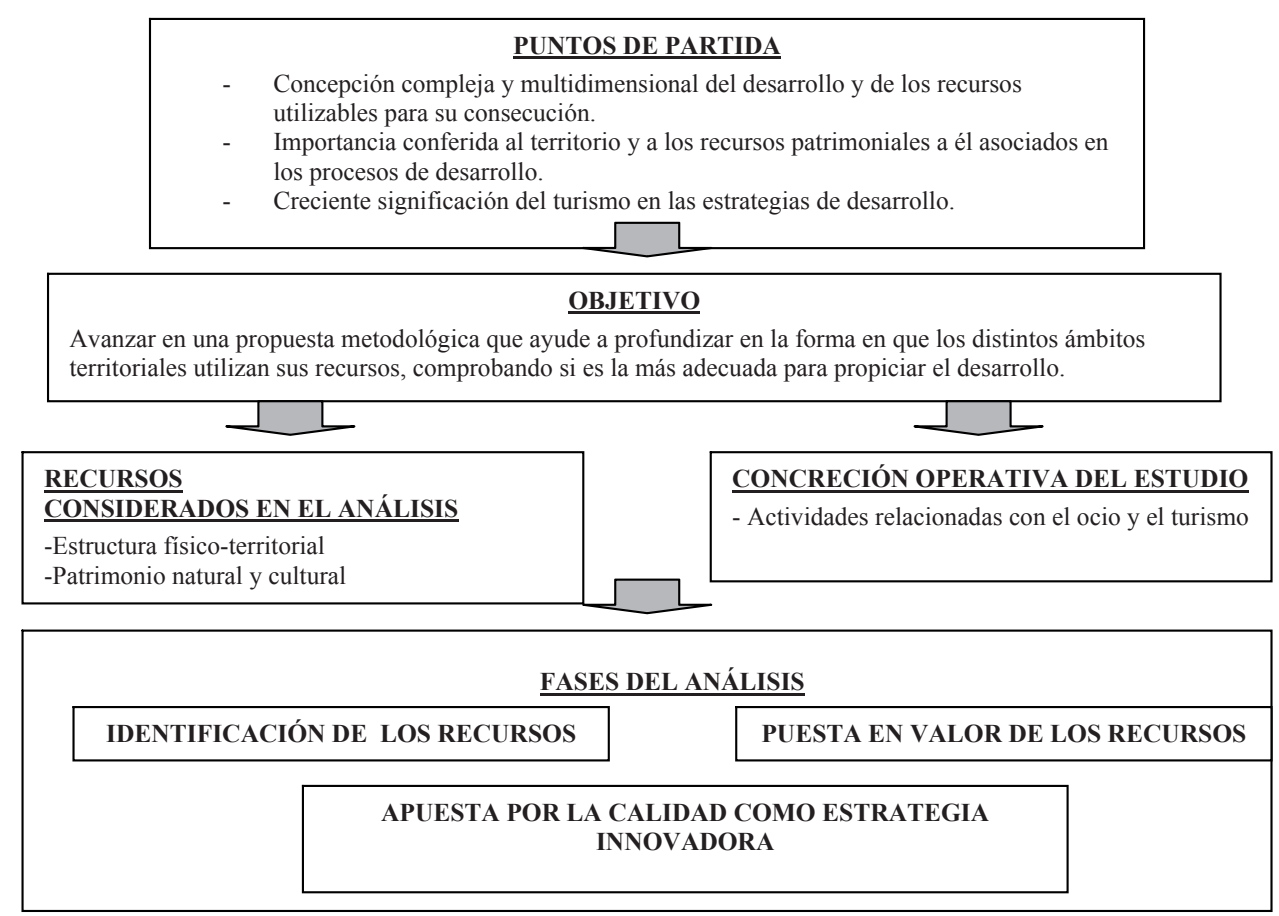

Figura 1. Planteamientos de la investigación.

\section{Identificación de los recursos para el desarrollo}

\subsection{La estructura físico-territorial: condicionante y recurso para el desarrollo}

Las nuevas relaciones espacio-temporales asociadas a la mundialización de la economía y al avance de las nuevas tecnologías de la comunicación llevaron a augurar el final del territorio y las distancias como factores condicionantes de los procesos de desarrollo. Unos presagios que parecen haberse cumplido a la inversa si atendemos a la creciente revitalización de la dimensión territorial como contrapunto al vértigo globalizador. En un mundo cada vez más interconectado y homogeneizado, los recursos genéricos — de carácter deslocalizable - pierden peso, al tiempo que se refuerza la dimensión territorial, depositaria de recursos específicos que son los que marcan las diferencias y acrecientan la competitividad en el contexto socioeconómico actual. En estas nuevas circunstancias, se refuerza el papel de aquellos recursos patrimoniales anclados en el territorio, de carácter único e irrepetible, en las estrategias de competitividad y excelencia turística. Se trata de 
destinos que utilizan la diferenciación y la autenticidad como estrategias de mercadotecnia: son los casos del turismo cultural-urbano y del turismo rural frente al turismo de sol y playa. El territorio pasa así de ser considerado un agente pasivo o mero soporte físico de los procesos de desarrollo a constituir un agente activo y dinámico que contribuye, además, a la generación de ventajas competitivas (Ferrao, 1996; Velt, 1996)

Este creciente protagonismo asignado al territorio en los procesos de desarrollo no se ha visto acompañado de la aparición de propuestas metodológicas sistemáticas que permitan identificar los recursos territoriales disponibles en cada ámbito. Es más, cuando se analizan tales recursos, suele ponerse el acento en los aspectos intangibles de la dimensión territorial (concertación social, saber hacer, cultura compartida...), prestando menos atención a su dimensión física, que aparece como mero soporte de las relaciones socio-culturales y de la propia actividad económico-productiva. Pero lejos de ser una llanura isotrópica el territorio presenta rugosidades (diferencias orográficas, red de asentamientos, infraestructuras...) que han de ser tenidas en cuenta en tanto que son matrices territoriales básicas que refuerzan la idiosincrasia de cada territorio, permiten o dificultan la puesta en valor de sus recursos patrimoniales e interponen facilidades y/u obstáculos para la consecución de un modelo de desarrollo equilibrado y, dentro de él, de una explotación turística racional y sostenible.

Como ha señalado Florencio Zoido (Zoido et al., 2001, 15): «el territorio es escenario y soporte fundamental de las actividades de la sociedad que lo tiene adscrito, que se asienta en él, lo ocupa y lo utiliza, estableciendo para ello una determinada disposición física y unas pautas de ordenación que posibilitan, a la vez que son consecuencia de esa implantación, el aprovechamiento del espacio en el que se vive». En la argumentación general de este artículo, conseguir que el territorio como tal contribuya a un desarrollo turístico racional e integrado depende tanto de la disposición u orden físico generado por su ocupación y utilización, como de su capacidad de proyección futura merced a la implementación de políticas, planes y programas (figura 2)

Con relación al orden físico-territorial, reviste un especial interés el análisis del emplazamiento y la situación de cada ámbito respecto a estructurantes territoriales básicos como la disposición de las unidades de relieve, la red hidrográfica, el sistema de asentamientos y la red viaria. A lo largo de la historia, las unidades de relieve han actuado como corredores o fronteras territoriales, según los casos, contribuyendo a la conformación de especificidades territoriales que están en la base de la idiosincrasia cultural de cada ámbito y del patrimonio cultural heredado. Otro tanto cabe señalar respecto a otros recursos territoriales básicos susceptibles de ser activados para el desarrollo turístico: el patrimonio natural y las panorámicas del paisaje, que guardan una estrecha relación con la disposición del relieve. A lo anterior se suma el papel desempeñado por la configuración orográfica en la disposición del sistema de asentamientos y en el trazado de la red viaria, que además de constituir otros dos recursos territoriales básicos, se erigen en condicionantes de primer orden para la generación de sinergias territoriales que permitan la utilización y gestión supramunicipal de los recursos disponibles para el turismo.

El análisis del sistema de asentamientos como un recurso para el desarrollo, en general, y para la promoción del turismo en particular, implica la consideración de varias facetas relacionadas con la estructura y morfología del poblamiento. Una estructura de asentamientos equilibrada en cuanto a sus tamaños poblacionales facilita las relaciones y la difusión de conocimientos que resultan indispensables para propiciar procesos de desarrollo en los núcleos de menor rango (municipios rurales y ciudades pequeñas y medias) donde el turismo apoyado en la idiosincrasia territorial adquiere un especial protagonismo; por el contrario, la macrocefalia urbana se erige en un obstáculo para la activación y/o difusión de tales procesos. Tanta importancia como la estructura adquiere la morfología de la red 


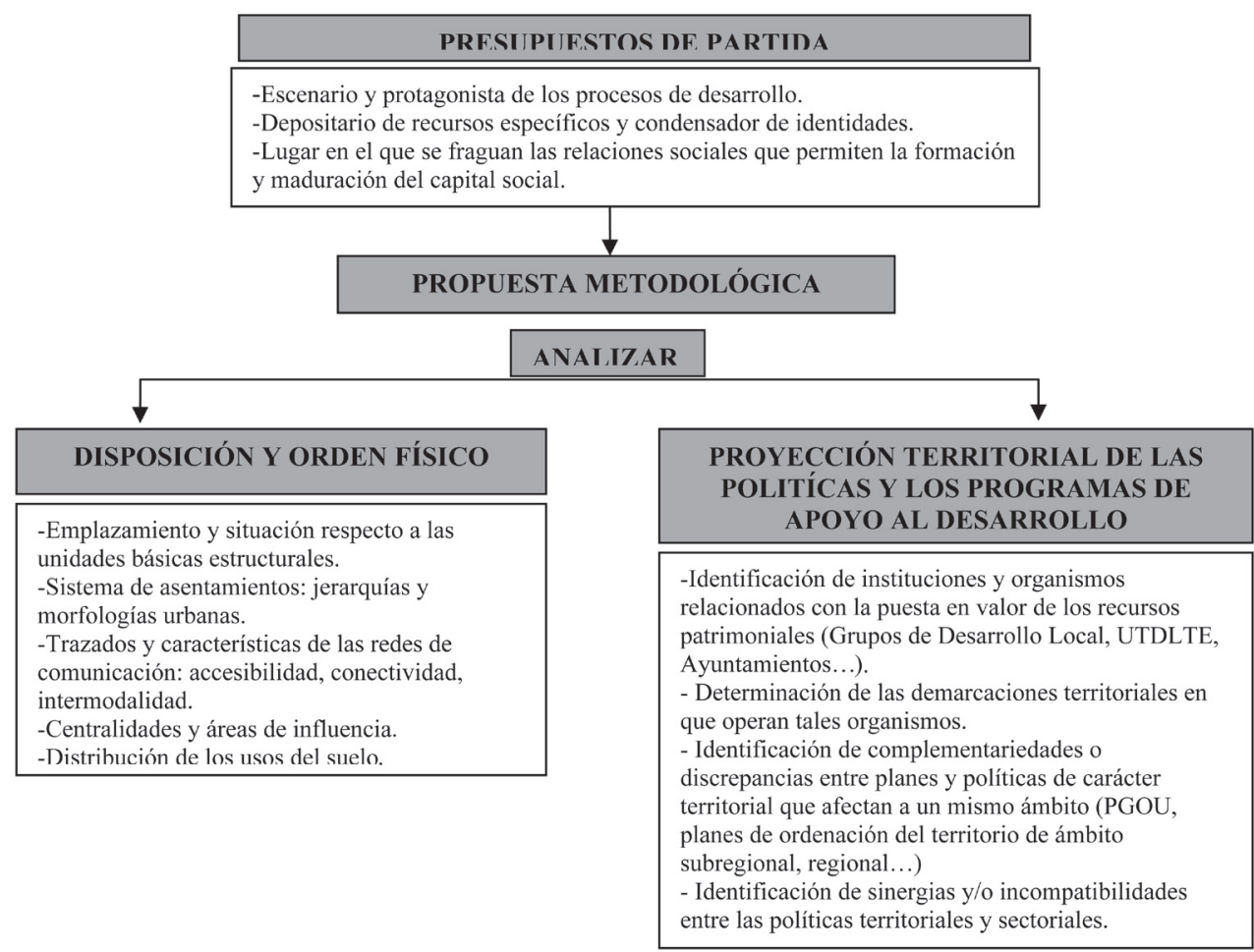

FIGURA 2. La estructura físico-territorial como recurso para el desarrollo.

de asentamientos, siendo de sobras conocida cómo la dispersión espacial facilita el desarrollo al tiempo que la concentración lo inhibe. Un aspecto éste que adquiere una especial relevancia en la configuración de itinerarios y rutas turísticas, así como en la constitución de redes de ciudades para la promoción de destinos turísticos supramunicipales como el promovido por el Plan Turístico de Ciudades Medias del Interior de Andalucía.

La estructura y disposición territorial de los asentamientos guarda una estrecha relación con el denominado sistema relacional, integrado por las infraestructuras de transporte y comunicaciones que constituyen las redes básicas que permiten la articulación territorial y la conversión de los recursos patrimoniales existentes en productos turísticos. No puede olvidarse, a este respecto, que una buena infraestructura viaria constituye una condición necesaria, aunque no suficiente, para el dinamismo económico y la puesta en valor de los recursos. Respecto a las redes de comunicaciones, interesará analizar la accesibilidad y conectividad de cada ámbito, constituyendo un recurso básico la presencia de una red intermodal integrada por diferentes medios de comunicación (carretera, ferrocarril, puerto, aeropuerto) cuya complementariedad refuerza las sinergias territoriales. Ello remite a otros aspectos de la estructura territorial que resultan cruciales para el desarrollo: los niveles de centralidad territorial y la distribución espacial de las áreas de influencia que, además de otros aspectos, permiten la gestión supramunicipal de los recursos disponibles y la organización de su puesta en valor. 
El estudio de la estructura territorial se completa con la distribución de los usos del suelo. Interesará, en primer lugar, analizar la adecuación de tales usos a las características y dinámicas del medio natural. Se trata de uno de los principales aspectos que hay que tener en cuenta no sólo para contar con un entorno de calidad, tanto ambiental como paisajística, sino para la prevención de riesgos de naturaleza catastrófica y para la minimización de sus potenciales efectos (deslizamientos de tierras, subsidencias del terreno, inundaciones...), que afectan a la seguridad humana, concepto que se está aplicando cada vez más generalizadamente y que está muy directamente relacionado con el desarrollo y la calidad de vida (Petitford, 1996; Trickner, 1995; Pérez de Armiño, 2002...). Un espacial interés reviste, por otra parte, el estudio de la distribución territorial de los principales usos (residencial, industrial, terciario, turístico...) atendiendo a aquellas situaciones de competencia por la ocupación y de desorden territorial y paisajístico que redundan en detrimento de otros recursos patrimoniales básicos (cultural, natural...) inhibiendo sus posibilidades de puesta en valor, al tiempo que merman la calidad de vida de los ciudadanos. Una atención especial merece, en este sentido, el estudio de las expansiones urbanísticas recientes y su engarce con el tejido histórico (en cuanto a proporciones, formas, volúmenes y configuraciones paisajísticas...). Se trataría, en suma, de analizar las relaciones existentes entre la organización física de cada ámbito y sus principales recursos patrimoniales comprobando, a su vez, si su disposición facilita la activación de tales recursos y potencialidades o, por el contrario, está impidiendo o minimizando su puesta en valor.

También es necesario dedicar una especial atención al suelo empresarial relacionado con los usos turístico-culturales, analizando la oferta de suelo y su relación con la demanda de equipamientos e industrias culturales, comprobando si está debidamente equipado y atendiendo a su ubicación con relación a otros usos con el objeto de evitar situaciones de competencia y desorden territorial que redunden, como se ha dicho, en un deterioro del paisaje y, a la postre, en detrimento de la puesta en valor de recursos patrimoniales básicos con fines de ocio y turismo.

Teniendo en cuenta, por otra parte, que el desarrollo más que una meta constituye un camino que necesita constantemente redefinir sus objetivos y estrategias (Fernández Salinas, 2003), interesará así mismo analizar las proyecciones futuras del territorio y del desarrollo atendiendo, de un lado, a las implicaciones territoriales de las propuestas planteadas por los agentes sociales e institucionales relacionadas con la valorización de los recursos y, de otro, a la prospectiva territorial de las políticas, planes y programas. Respecto a los primeros, además de la identificación de los principales agentes (ayuntamientos, administración regional, grupos de desarrollo local, asociaciones...) y del análisis de las implicaciones territoriales de sus programas de desarrollo, interesará reparar en las circunscripciones territoriales en que éstos operan con vistas a comprobar posibles coincidencias o divergencias en sus respectivas áreas de influencia. Es muy habitual que en un mismo territorio operen distintas instituciones con diferentes niveles y ámbitos de competencia, lo que redunda en una merma de su operatividad, no sólo por el desconocimiento mutuo de medidas cuyos objetivos son similares, sino porque provoca una confusión en sus potenciales beneficiarios (empresas y/o ciudadanía, según los casos) que no tienen claro dónde acudir para buscar apoyo institucional y financiero a sus proyectos.

Lo anterior remite a la necesaria colaboración interinstitucional en la gestión y la puesta en valor de recursos territoriales y, a la postre, en un avance hacia la gobernanza. Un aspecto, este último, para el que también reviste un especial interés la comprobación de posibles complementariedades y/o contradicciones entre distintos planes, tanto entre aquellos que inciden en un mismo territorio a distintas escalas (planes generales de ordenación urbana, planes de ordenación del territorio de ámbito subregional o regional...), como entre éstos 
y los planes sectoriales con incidencia territorial. Es necesario comprobar, a este respecto, si tales planes comparten filosofía y objetivos respecto a la ordenación y gestión de las actividades turísticas, el tratamiento que hacen de los recursos patrimoniales disponibles y el grado de coincidencia de sus proyecciones futuras.

\subsection{Identificación del patrimonio natural y cultural como recursos para el desarrollo y el turismo}

La creciente importancia económica, social y cultural de la puesta en valor de los recursos patrimoniales ha sido reconocida por diferentes disciplinas y se manifiesta en la discusión sobre el desarrollo endógeno (Greff, 1990; Greenfield, 1996; Mose y Weixlbaumer, 2003; Vázquez Barquero, 1993 y 1999; Voth, 2006). Bajo la presión de la creciente competencia, los territorios más innovadores buscan nuevas oportunidades activando sus recursos genéricos para convertirlos en específicos (Rallet, 1996; Crevoisier, 2001; Albertos-Caravaca-MéndezSánchez, 2004), lo que implica una revalorización del patrimonio natural y cultural.

Tal vinculación del patrimonio al desarrollo ha trascendido del mundo de la investigación al ámbito institucional. En este último sentido resulta significativo que tanto organismos internacionales, como la UNESCO y el Consejo de Europa, como otros nacionales y regionales de diversos países europeos hayan aumentado sus declaraciones sobre bienes culturales y espacios naturales protegidos, señalando la necesidad de poner en valor tales recursos al considerarlos básicos para propiciar el desarrollo. Constituyen ejemplos representativos los casos de Gran Bretaña, donde se han realizado estudios a escala europea sobre las estrechas relaciones entre cultura, economía y territorio (Ilbery y Kneafsey 1998; Graham-Ashworth-Tunbridge, 2000); y de Francia, donde despierta un gran interés el debate sobre el término de terroir (terruño) y la revalorización de productos locales como parte del patrimonio cultural para el fomento de la economía regional (Delfosse, 1997). Además, planteamientos similares se han ido difundiendo también por otros países como España y Alemania (Gómez de la Iglesia, ed., 2001; Voth, 2003).

Tal revalorización de los recursos patrimoniales se relaciona, a su vez, con la ya citada generalización de la sociedad del ocio y la mayor disponibilidad de tiempo libre, que ha llevado a una creciente utilización del patrimonio natural y cultural como activos para el de desarrollo, preferentemente a través de su utilización por el turismo. Un aspecto, este último, que no es nuevo en el ámbito urbano donde el turismo cultural goza de una dilatada trayectoria y que en los últimos decenios se ha expandido al ámbito rural al amparo de programas (caso de las iniciativas Leader y Proder) que incluyen una fuerte apuesta por el turismo rural como estrategia de desarrollo.

También se ha comentado como los procesos de revalorización del patrimonio natural y cultural para el desarrollo de los territorios son un tema aún poco tratado desde una perspectiva investigadora, siendo escasos los análisis empíricos centrados en dicho objeto y aún más escasas las propuestas metodológicas que ayuden a su sistematización. Dado que la identificación de los recursos constituye la primera etapa para su utilización en proyectos turísticos y en programas de desarrollo, la propuesta metodológica que aquí se plantea parte de la identificación de aquellos recursos patrimoniales considerados relevantes por: a) las instituciones encargadas de velar por la conservación del patrimonio en su doble y artificial diferenciación entre patrimonio cultural y natural, b) otras instituciones territoriales y sectoriales que incluyen la ordenación y/o gestión de los recursos en sus planes y programas y c) la propia sociedad civil, principal depositaria de tales recursos y valedora de su autenticidad (figura 3). 
- Generalización de la socicdad del ocio.

-Concienciación ciudadana sobre la necesidad de preservar el medio ambiente y el paisaje.

- Demanda de recursos específicos de cada territorio.

- Revalorización del patrimonio natural y cultural como activos para el desarrollo.

\section{PROPUESTA METODOLÓGICA}

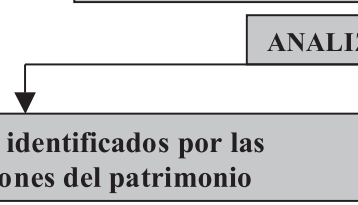

Recursos identificados por las
instituciones del patrimonio

Ámbito internacional:

-UNESCO (Lista de Patrimonio Mundial, Zonas

Reservas de la Biosfera).

-Consejo de Europa (Itinerarios Culturales Europeos).

Ámbito nacional:

-Ministerio/Consejerías de Cultura (Bienes de Interés

Cultural y figuras equivalentes).

-Ministerio/Consejerías de Medio Ambiente (sujeción a

alguna figura relacionada con la conservación del

patrimonio natural).

\section{Recursos identificados por otros organismos e instituciones}

Por las instituciones implicadas con la ordenación del territorio:

-Catálogos en planes urbanísticos y territoriales.

Por las instituciones agrarias y rurales:

-Identificación de recursos patrimoniales por parte de las medidas de politica agraria.

-Elaboración de guías, inventarios y catálogos del patrimonio existente en el medio rural

\begin{tabular}{|l|}
\hline \multicolumn{1}{|c|}{ Por la sociedad civil } \\
\hline -Identificación de los recursos patrimoniales. \\
-Valoración de la utilización de tales recursos con fines turismos. \\
-Relaciones entre turismo y calidad de vida. \\
-Creación de asociaciones y redes de defensa de los recursos patrimoniales. \\
-Otros. \\
\hline
\end{tabular}

FIGURA 3. Identificación del patrimonio natural y cultural como recurso para el desarrollo.

Comenzando con los recursos patrimoniales distinguidos por las instituciones, es preciso diferenciar entre aquellos catalogados por las instituciones directamente relacionadas con la protección y gestión del patrimonio (tanto cultural como natural) y los considerados por otros organismos e instituciones públicas en sus planes y programas. Con relación a los primeros, se trata de distinciones que suelen estar amparadas en alguna figura de protección de la normativa reguladora del patrimonio histórico-cultural (monumento, jardín, conjunto histórico, zona patrimonial...) y natural (parque natural, parque nacional, paisaje protegido, reserva natural...). En ambos casos, el reconocimiento institucional acrecienta el valor añadido de tales bienes por cuanto se suele asociar a una garantía de calidad y autenticidad, que se incrementa sobre manera en caso de gozar de un reconocimiento internacional merced a su inclusión en la Lista de Patrimonio Mundial de UNESCO o su declaración como Reserva de la Biosfera, también avalada por UNESCO.

Las posibilidades de activación de tales recursos patrimoniales institucionalmente reconocidos están estrechamente relacionadas con las características de cada figura en cuestión. 
En el caso del patrimonio cultural hay nuevas figuras en numerosas comunidades autónomas españolas especialmente indicadas para la promoción turística de los territorios como el parque cultural o la zona patrimonial en los que se apoyan, aunque no necesariamente, muchas iniciativas de territorios museo. Otro tanto cabe señalar respecto al patrimonio natural, siendo crucial en este caso diferenciar entre aquellas figuras que priman la conservación sobre el desarrollo (reserva natural, parque nacional...), lo que en muchos casos supone un impedimento para su utilización por el turismo, de aquellas otras que persiguen el desarrollo de los territorios utilizando para ello todos los recursos patrimoniales disponibles (caso de la figura de parque natural).

Sin alcanzar la potencia de la mercadotecnia o, en su expresión anglosajona, márketing territorial y turístico asociado a las figuras de protección legales del patrimonio histórico y natural, es preciso tener también en cuenta los recursos patrimoniales reconocidos por otros organismos e instituciones relacionadas con la ordenación del territorio y otras administraciones sectoriales. En el primer caso, reviste un gran interés reparar en los elementos catalogados para su protección por parte de la normativa urbanística en los planes generales de ordenación urbana, así como los considerados en los planes de ordenación del territorio de ámbito regional y/o subregional. A título de ejemplo, el Plan de Ordenación del Territorio de Andalucía (Decreto 206/2006) hace referencia a un «sistema de patrimonio territorial de Andalucía» que integra los espacios naturales y los bienes culturales, las vías pecuarias, las ciudades y pueblos históricos y la arquitectura popular, y presta mención específica a determinados ámbitos «con especiales valores naturales y paisajísticos» como Las Alpujaras, la Serranía de Ronda o la Vega del Guadalhorce, entre otros. Más allá van algunos planes de ordenación del territorio de ámbito subregional, como el de la aglomeración urbana de Granada, que incluyen un catálogo de elementos patrimoniales en el que en parte se ha apoyado la reciente propuesta de declaración de la Vega de Granada como Bien de Interés Cultural.

Una especial relevancia reviste igualmente el reconocimiento de los recursos patrimoniales presentes en el territorio que hacen algunas administraciones sectoriales como la ambiental o la agraria. En cuanto a la administración ambiental, además de la identificación patrimonial de determinados recursos y/o espacios sujetos a alguna figura de protección a la que antes nos referimos, reviste un especial interés comprobar el tratamiento que merecen los recursos patrimoniales presentes en cada territorio por parte de planes de ordenación de los recursos naturales, los planes rectores de uso y gestión, los planes de desarrollo sostenible o la propia normativa de evaluación de impacto ambiental. En lo que se refiere a la agricultura, hay que comenzar resaltando la evolución experimentada por los programas de política agraria desde medidas centradas en su faceta productiva sin tener en cuenta sus valores patrimoniales (Silva Pérez, 2008), hasta planteamientos más recientes de carácter territorial, con un sesgo patrimonialista claro algunos casos. Un ejemplo de esto último es la elaboración de catálogos de recursos por parte de las instituciones de la agricultura - caso de la Guía para la puesta en valor del patrimonio del medio rural publicada en el año 2000 por la Consejería de Agricultura de la Junta de Andalucía- o el reconocimiento de paisajes y entornos agrarios de elevado valor cultural e histórico por parte de algunos programas agroambientales diseñados para zonas específicas como los paisajes de la caña de azúcar del litoral mediterráneo, las dehesas, los castañares, los paisajes del membrillo o las huertas tradicionales de los ruedos de los pueblos (Silva Pérez, 2008). Respecto a las medidas vinculadas al desarrollo rural, es preciso finalmente destacar el papel desempeñado por los grupos de desarrollo rural que gestionan las áreas Leader y Proder en el reconocimiento de recursos patrimoniales poco considerados por las instituciones del patrimonio y muy arraigados en los territorios (arqueología indus- 
trial, patrimonio etnográfico, arquitectura vernácula...). Y ello a través de la realización de catálogos e inventarios, incluyendo en algunos casos su puesta en valor por programas territoriales de desarrollo.

Si se parte finalmente del convencimiento de que todo modelo de desarrollo se fabrica desde el territorio, del carácter colectivo de los recursos patrimoniales y de que la garantía de autenticidad de tales recursos la aseguran las poblaciones locales, que además de ser las depositarias son las herederas directas de la cultura que les dio origen (Fernández Salinas y Romero Moragas, 2008), se habrá de concluir en su necesaria implicación en el modelo turístico a seguir. Un especial interés reviste, en este sentido, la identificación de los recursos patrimoniales existentes en cada ámbito, considerando no solamente el patrimonio protegido, sino también aquellos otros bienes menos perceptibles desde el exterior pero no por ello menos relevantes para el desarrollo. Por otra parte, de todos es sabido que la puesta en valor de los recursos patrimoniales al margen de los intereses y aspiraciones de las poblaciones locales repercute en su deterioro o banalización y redunda en una merma de la calidad de vida local. Es por ello por lo que también se hace preciso averiguar la percepción y aspiraciones que éstas tienen del turismo, indagando sobre aquellos aspectos relacionados con las consecuencias económicas, territoriales y socio-culturales de esta actividad (creación de empleo, conformación de guetos turísticos, posible pérdida de identidad cultural...) a través de la realización de encuestas y entrevistas tanto a aquellos agentes relacionados directamente con el sector como al conjunto de la sociedad civil.

\section{La puesta en valor de los recursos patrimoniales para el ocio y el turismo}

\subsection{Aspectos generales de la puesta en valor de los recursos patrimoniales para el ocio y el turismo}

Una de las vías más frecuentes de poner en valor los recursos patrimoniales es orientarlos hacia el ocio y el turismo cultural. Sin duda, éstos son dos campos claramente interrelacionados y que han adquirido una gran complejidad durante los últimos años. Los cambios culturales, las nuevas pautas de consumo o incluso los nuevos patrones de aceptación y significación social vienen dando al patrimonio cultural no sólo un protagonismo mayor, sino incluso un papel distinto y mucho más rico en su rol social.

No se trata de considerar todo el campo de los recursos patrimoniales en esta parte del trabajo, sino de aquellos que son objeto, al menos potencial, de su puesta en valor para satisfacer las nuevas demandas de los tiempos de ocio (bien sea en el territorio en el que se vive; bien visitando otros — turismo, excursionismo-).

En este sentido, interesa: a) identificar las infraestructuras turísticas para este espacio de ocio, b) la visibilidad de sus recursos, c) los productos obtenidos y d) avanzar en el proceso de identificar, valorar y matizar la calidad de tales infraestructuras, recursos y productos. No es objeto de estas líneas plantear una presentación del sector del turismo cultural, sino de repasar los aspectos más importantes en relación con los cambios recientes del turismo vinculados con los recursos patrimoniales. En otras palabras, no se obviará una referencia básica a las infraestructuras generales, pero el hincapié se pondrá en los problemas que supone convertir los recursos potenciales procedentes del patrimonio en productos que respeten sus valores y al mismo tiempo satisfagan las nuevas demandas sociales relacionadas con el tiempo de ocio y turismo.

Por otro lado, también debe ser reseñada la siguiente paradoja del turismo cultural frente a otras tipologías turísticas, y que debe ser tenida muy en cuenta al tratar aspectos relacionados con la calidad del turismo cultural. El turista (visitante que pernocta) y el 
excursionista (visitante que no pernocta) de carácter cultural se fideliza de forma muy distinta a como lo hace el de sol y playa. Este último, tenderá a regresar a los destinos en los que ha tenido una experiencia agradable y no se hayan traicionado sus expectativas previas. En el campo del turismo cultural, al contrario, cuanto más satisfechos se sientan sus clientes, mayor será su voluntad de conocer escenarios nuevos y recursos patrimoniales distintos. El turismo cultural, como ningún otro, tiene que plantearse una organización en red, ya que los efectos de su buena imagen y la satisfacción proporcionada repercutirá en otros territorios proveedores de productos culturales. Los responsables y gestores de este sector económico deben ser conscientes de que otros agentes, casi siempre desconocidos y a menudo muy lejanos, también trabajan para ellos. Se trata pues de un planteamiento complejo, pero que está creando sin duda nuevos retos al sector, al tiempo que la demanda no deja de crecer.

\subsection{Las infraestructuras para el ocio y el turismo}

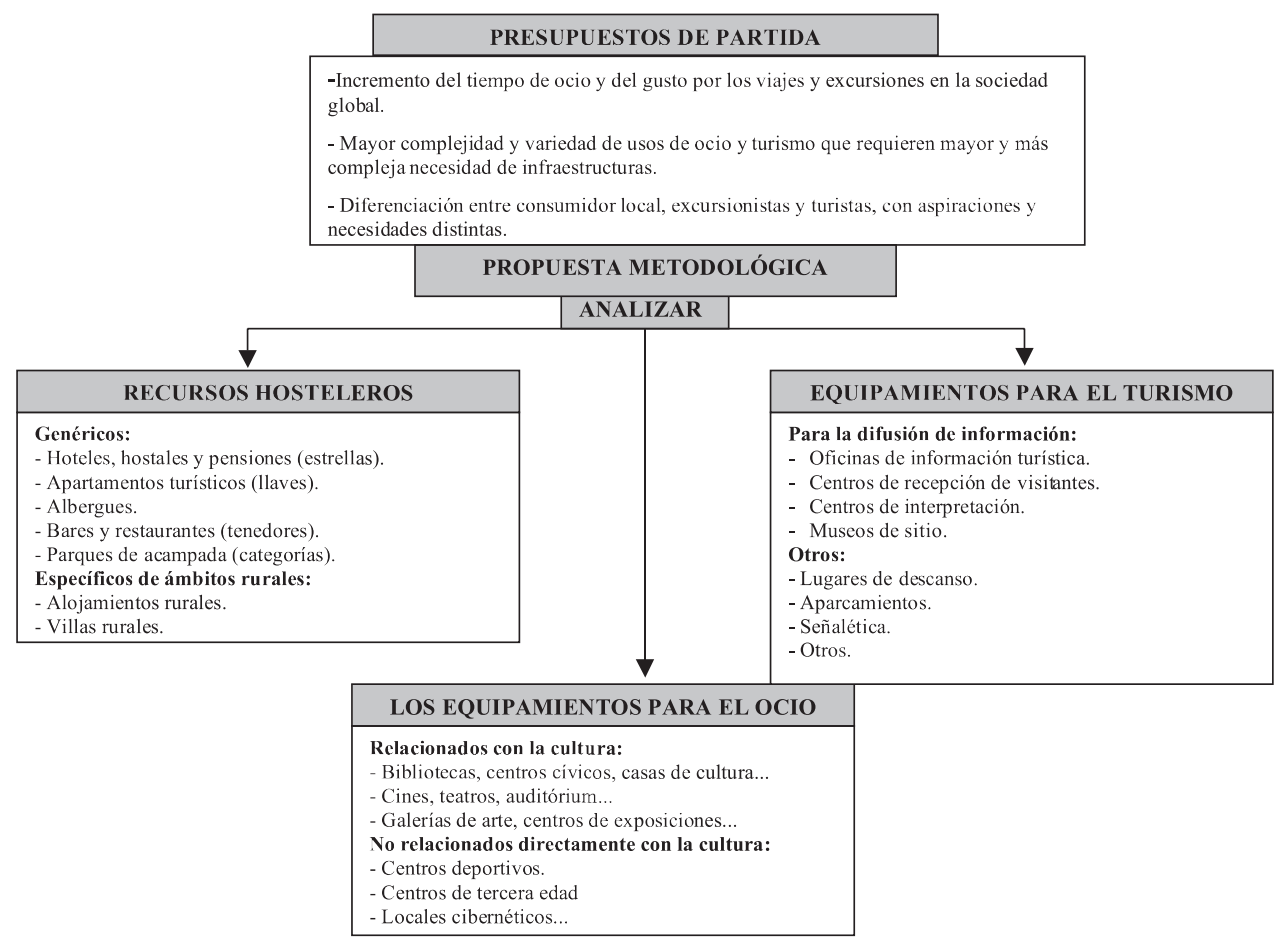

FIGURA 4: Identificación de infraestructuras para el ocio y el turismo.

\section{a) Los recursos hosteleros}

El análisis de los recursos turísticos posee métodos ensayados y probados satisfactoriamente desde hace varios decenios. De hecho, cualquier proyecto o plan de revitalización y modernización turística se centra antes que en otros aspectos en la identificación y valoración de estos recursos. Entre ellos, los recursos hosteleros son los mejor conocidos; y esto no sólo porque existan fuentes relacionadas con registros y registros de actividades 
económicas sometidas a impuestos, sino porque la propia vitalidad del sector depende de su capacidad para trascender su imagen a mercados externos (ver también más adelante el análisis de la visibilidad). Estas infraestructuras (salvo los bares y restaurantes), están especialmente ligadas al turista, es decir, como ya se ha dicho, al visitante que pernocta y que normalmente suele ser el principal objeto de las estrategias turísticas. Con esto, a menudo se desprecia o se relega a un lugar muy secundario la importancia del excursionista, aquel visitante que regresa a pernoctar a su domicilio habitual (o que pernocta en un hotel exterior al área analizada). Este hecho, provoca que se minusvalore en destinos turísticos próximos a áreas urbanas una fuente de visitantes mucho más desestacionalizada y numerosa que la de aquellos que proceden de orígenes lejanos.

El turismo rural, por su parte, ha adquirido una serie de características propias y diferenciadoras que lo hacen merecedor de comentarios también específicos: de un lado surge de una demanda distinta a la del turista que se aloja en un establecimiento hotelero convencional y, además, incluso aunque el turista rural posea una demanda patrimonial importante, normalmente está más interesado en otras expresiones culturales que no las monumentales tradicionales. Así, para este perfil turístico cobran especial importancia el patrimonio intangible (artesanía, gastronomía...) o el disfrute del paisaje y la interrelación de cultura y naturaleza.

\section{b) Los equipamientos para el turismo}

Los equipamientos para el turismo también han experimentado un notable cambio durante los últimos años. La generalización en Europa a partir de los años setenta de las teorías sobre interpretación del patrimonio y la implementación de planes que desarrollan sus métodos para extraer el verdadero significado del territorio y del patrimonio (lo que se ha dado en llamar la transmisión del alma de aquello que se está interpretando), ha generalizado todo un repertorio de equipamientos de distintos nombres, pero no siempre de muy diferentes contenidos y objetivos (centros de interpretación, museos de sitio, lugares de recepción de visitantes, etcétera). Así, las tradicionales oficinas de información turística también se han transformado en muchas ocasiones en verdaderas puertas del territorio en las que, además de ofrecer los tradicionales folletos turísticos, se pueden realizar reservas, adquirir productos de la zona y contemplar exposiciones, entre otros servicios. No obstante, el análisis debe completarse con otros equipamientos también demandados o, en todo caso, muy útiles para regular la llegada de visitantes: aparcamientos, lugares de descanso, señalética adecuada, etcétera.

\section{c) Los equipamientos para el ocio}

Los equipamientos para el ocio tienen que ver en la mayor parte de las ocasiones con la población residente. Se trata de contenedores destinados a satisfacer las necesidades de la política cultural local (bibliotecas, cines, teatros), aunque en no pocas ocasiones, y sobre todo en las grandes ciudades, su horizonte o área de atracción es mucho más amplio (teatro de la ópera de grandes ciudades, centros de grandes exposiciones, etcétera). Sin embargo, muchos de estos equipamientos para el ocio no tienen que ver directamente con la política cultural y patrimonial. Se trata sobre todo de instalaciones deportivas, cibernéticas, zonas de paseo, locales para la tercera edad, etcétera. Muchos de ellos, no obstante, si desarrollan indirectamente actividades culturales e incluso actuaciones de gran formato (por ejemplo, el uso de los estadios de fútbol para la celebración de conciertos), por lo que deben ser incluidos como potenciales recursos de infraestructura turística. 


\subsection{Análisis de la visibilidad de infraestructuras y recursos para el ocio y el turismo}

Ya se ha adelantado cómo la visibilidad de los recursos e infraestructuras es lo que convierte a éstos en productos turísticos (ver también epígrafe 3.4 y figura 5). Visibilidad y mercadotecnia son dos conceptos que están muy próximos uno del otro, pero la vocación prioritariamente económica, sobre todo del primero de los términos, incorpora una dimensión que trasciende lo meramente económico al incluir aspectos simbólicos que son intrínsecos a los recursos culturales y patrimoniales. Éstos tienen la capacidad de generar identidad y, por lo tanto, son más frágiles y alterables que otros recursos económicos. La visibilidad de los recursos culturales ha de alcanzar un equilibrio, nunca fácil, entre la capacidad de transmitir los valores de un bien cultural para hacerlo atractivo al turismo cultural y, al tiempo, tener en cuenta que posee una capacidad de acogida limitada y que deben evitarse las situaciones que se han dado en denominar «morir de éxito».

Para poder determinar la visibilidad de los recursos, servicios e infraestructuras turísticos y de ocio ligados al patrimonio no existen metodologías de larga trayectoria; ni siquiera ha sido un objetivo presente en buena parte de los estudios específicos de carácter turístico. A efectos de este trabajo se propone un análisis de la visibilidad de los recursos patrimoniales tal y como se expresa en la figura 5:

a) La visibilidad básica de los bienes patrimoniales viene determinada por el reconocimiento de instituciones oficiales (ya presentada en la figura 3). Algunas de tales instituciones son de carácter internacional y ofrecen repertorios de bienes patrimoniales de interés universal y de gran reconocimiento por parte de la comunidad científica. Éste es el caso de UNESCO y algunos de sus registros más conocidos (la Lista del Patrimonio Mundial, la red de Zonas Reserva de la Biosfera, etcétera). También existen varias instituciones europeas que poseen sus propios listados de bienes patrimoniales. Algunas de ellas mantienen el interés científico en sus recuentos (sobre todo algunos repertorios presentes o futuros de la Unión Europea - Lugares de Interés Comunitario, LICs; Patrimonio Europeo-) y otros tienen la vocación de crear condiciones de hermanamiento y productos turísticos entre las distintas regiones europeas (caso de los Itinerarios Europeos del Consejo de Europa).

La visibilidad oficial en la escala española viene dada por diferentes tipos de fuentes. Algunas poseen una base legal de referencia; así sucede con los bienes de interés cultural, emanados de los principios de la Ley de Patrimonio Histórico Español 16/1985 o de los diferentes catálogos autonómicos que se basan en la doctrina legal propia (por ejemplo, los bienes inscritos en el Catálogo General del Patrimonio Histórico Andaluz). A estos se pueden añadir los repertorios de bienes naturales, dado que cualifican y complementan los recursos anteriores en el campo del ocio y del turismo.

Los catálogos e inventarios del planeamiento urbanístico y territorial suponen un cuarto nivel tras el internacional, el nacional y el autonómico en la visibilidad de recursos oficiales. Poseen una gran variedad de tipologías y, sobre todo, de criterios para su selección, pero sin duda son importantes en los procesos de protección y puesta en valor del patrimonio en la escala local.

Por último, existen también guías oficiales de equipamientos e infraestructuras (Guía Oficial de Hoteles, Guía Oficial de Camping....), que completan la visibilidad oficial de los recursos turísticos.

b) La presencia en guías de y obras de referencia de carácter privado, aunque con alguna excepción, es una buena medida de la visibilidad de los recursos culturales utilizada para el ocio y turismo. Aunque algunas exigen el pago previo de un canon de publicidad, son no pocas las que desde un punto de vista independiente valoran la calidad de aquellos recursos que consideran de mayor interés. 


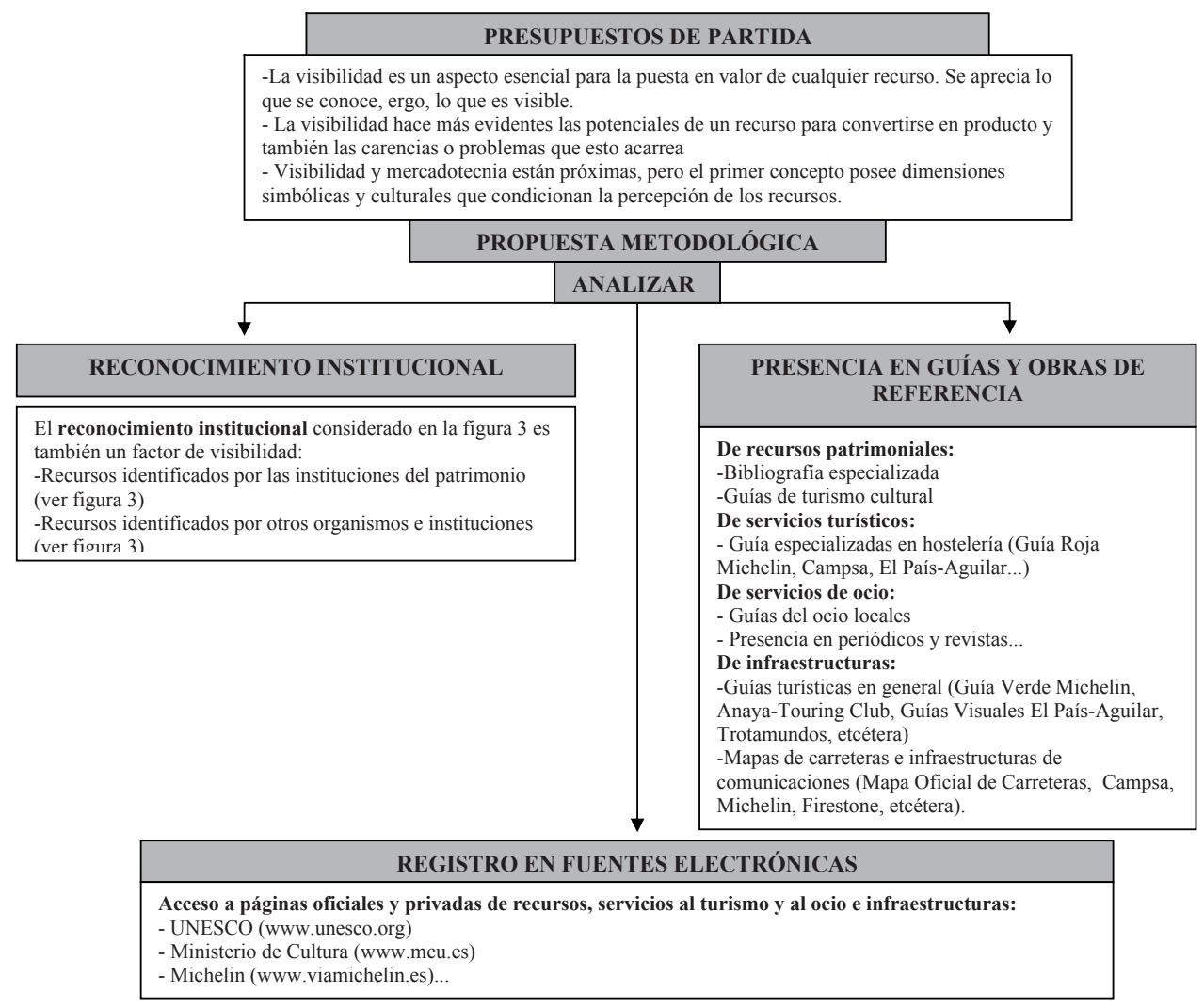

FiguRa 5. Identificación de visibilidad de infraestructuras y recursos para el ocio y el turismo.

Las guías pueden estructurarse según sus distintos perfiles: guías de recursos patrimoniales, de servicios turísticos, de servicios de ocio y de infraestructuras. En las primeras se incluye todo un elenco de publicaciones que incorpora desde monografías especializadas sobre recursos culturales a guías de turismo cultural elaboradas con criterio patrimonial. Respecto a los servicios turísticos, la información más relevante versará sobre servicios hosteleros (hoteles, hostales, pensiones, restaurantes...) y vendrá también de guías especializadas y que operan con independencia (Guía Roja Michelin, Guía Campsa, El País-Aguilar, etcétera). También son de interés las referencias dedicadas al ocio; para ello las fuentes básicas son las guías de ocio locales, así como las referencias que aparecen en la prensa diaria y otras publicaciones especializadas.

Respecto a las infraestructuras turísticas, la información básica (oficinas de turismo, estaciones de autobuses, aeropuertos, etcétera) aparece con frecuencia en las guías turísticas en general, al tiempo que gran parte de los datos sobre infraestructuras viarias y de comunicación se reflejan en los mapas turísticos (Michelin, Firestone, Guía Campsa, etcétera).

c) A este elenco de fuentes hay que añadir las fuentes electrónicas o digitales. La mayor parte de las infraestructuras y recursos poseen repertorios detallados en las páginas 
web de organismos oficiales (UNESCO, Ministerio de Cultura, Consejerías de Cultura, de Turismo, etcétera) que completan los registros y ofrecen una información muy valiosa sobre la visibilidad de estas infraestructuras y recursos.

\subsection{Los productos turísticos}

Ya se ha señalado la necesidad de convertir en productos turísticos los recursos potenciales, entre ellos el patrimonio, de cara a su implementación en los procesos de desarrollo. Los productos turísticos que ponen en valor el patrimonio tienen una fuerte componente territorial. Además, a pesar de las escasas valoraciones generales de este tipo de iniciativas, es de destacar la complejidad y compromiso de los actores locales en propuestas de territorios-museo, fórmulas de activación general del patrimonio con una importante componente estratégica en sus modelos de gestión y potenciales generadores de capitales sociales locales. Los ecomuseos han perdido actualidad en relación con las figuras antes citadas y también en relación con los denominados parques culturales y otras fórmulas similares que se basan en las leyes patrimoniales de algunas comunidades autónomas y que tratan de establecer modelos territoriales de gestión del patrimonio cultural basados en la experiencia de los parques naturales; esto es, con la presencia de consejos rectores que desarrollen proyectos e iniciativas encaminadas a desencadenar procesos de desarrollo territorial.

También en esta línea de reforzamiento de la perspectiva territorial, las rutas culturales y turísticas han adquirido una gran relevancia. No se trata sólo de los grandes itinerarios culturales reconocidos por UNESCO (Camino de Santiago, Ruta de la Seda, etcétera), sino también de rutas de significado europeo (Itinerarios Culturales Europeos como El Legado Andalusí) u otras de dimensión regional (por ejemplo, la Ruta Bética Romana) o comarcal (Ruta del Tempranillo). En este sentido, la puesta en valor del patrimonio debe reforzar el excursionismo cultural, tal y como ya se adelantó, un contexto de interpretación que se relaciona con los públicos regionales y que sin duda es el ámbito de mayor crecimiento durante los últimos años y con un importante futuro.

Por último, entre los productos relacionados con el turismo y el ocio en relación con los recursos patrimoniales ha de citarse la celebración de eventos. Por su naturaleza también son de características muy distintas, y van desde las grandes celebraciones como los años santos compostelanos, a la celebración de ferias, jornadas gastronómicas u otras propuestas relacionadas con la cultura (material y muy a menudo inmaterial). Los eventos acentúan la visibilidad del territorio y de su patrimonio, aumentan su capacidad de atracción de turistas y excursionistas y refuerzan la autoestima de los territorios en los que se desarrollan. Por el contrario, muchos eventos pueden terminar banalizando los recursos patrimoniales y ofreciendo productos estandarizados o basados en valores falsos (mercados medievales y similares, sobre todo).

\subsection{La calidad de las infraestructuras, de los recursos y de los productos}

Una vez identificados infraestructuras y recursos, valorada su visibilidad, y establecido un registro de los productos obtenidos a partir de ellos, el círculo se completa con la determinación de su calidad (de infraestructuras, recursos y productos). Este es un campo aún difícil de medir y valorar, especialmente en la perspectiva territorial. En todo caso, puede destacase la marca Parque Natural, que en un contexto como el andaluz fue creada por la Consejería de Medio Ambiente de la Junta de Andalucía en 2004 (Orden de 15 de diciembre de 2004) a fin de otorgar un marchamo de calidad a las empresas que cumplen determinados requisitos productivos y ambientales comprobados por la entidad certifica- 
dora: la Fundación ANDANATURA. Se trata, pues, de una estrategia de mercadotecnia o márketing territorial amparada en la calidad, que puede resultar de gran relevancia en la activación socioeconómica de los parques naturales y que está teniendo una aceptable acogida como lo demuestra el hecho de que existan 825 productos y 168 empresas certificadas en sus poco más de dos años de vigencia. Se trata, en su mayoría, de empresas relacionadas con la promoción del turismo (90 empresas especializadas en alojamientos, restauración, senderismo, visitas guiadas...), seguidas de las dedicadas a la producción y transformación de productos de la agricultura (59 empresas) y, en menor medida, de aquellas especializadas en la fabricación de artesanías (19 entre empresas de cerámica, artículos de corcho, cosméticos, etcétera) (Silva y otros, 2007).

Respecto a la calidad turística hay acreditaciones específicas que vienen utilizándose, y mejorándose, durante los últimos decenios. Alguna como la del Instituto Español para la Calidad Turística ( $Q$ de Calidad Turística) está teniendo una importante proyección en los escenarios turísticos (y no sólo del turismo cultural, sino del turismo en general). Programas de calidad integral también vienen implementándose cada vez de forma más organizada y como medio de mejorar ámbitos turísticos en reconversión o emergentes (SICTED, Sistema Integral de Calidad Turística en Destino). Por otro lado, también se pueden utilizar sistemas de acreditación estándar (Aenor, ISO 9001, ISO 14001, etcétera).

Algunas de las guías de referencia citadas en el punto 3.3 apartado b), poseen mecanismos propios e independientes de valorar la calidad de los recursos turísticos. Entre las más destacadas y ya con una cierta tradición en España hay que señalar el sistema de estrellas para los restaurantes de la Guía Roja Michelin, la Guía del Grupo Gourmets, y otros de características similares.

Es preciso desarrollar metodologías que mejoren el conocimiento de la calidad en el aprovechamiento de los recursos patrimoniales en la perspectiva territorial, de forma que se combinen las acreditaciones a recursos concretos con valoraciones de la calidad de forma genérica, desglosada y coordinada para el conjunto de los recursos de un territorio (municipio, comarca, etcétera). Sin embargo, éste parece un objetivo aún lejos de asumir por los proyectos de puesta en valor y de evaluación de los recursos patrimoniales.

\section{Consideraciones finales}

Conocer en qué forma el patrimonio coadyuva al desarrollo es una misión difícil y con escasos trabajos publicados. La bibliografía al uso lleva un cierto proceso de estancamiento. La irrupción de títulos y trabajos de principios y mediados de los años noventa no parece haber sabido evolucionar, probablemente a causa de la difícil evaluación de políticas y proyectos. La visibilidad y la calidad, dos conceptos que no son nuevos y que proceden de campos distintos, cobran protagonismo en el discurso del patrimonio como factor de desarrollo en los últimos años. La primera está muy relacionada con aspectos del mundo del comunitarismo y expresa la necesidad de los grupos minoritarios para ser menos vulnerables y ser más reconocidos. El segundo tiene un amplio cúmulo de aportaciones ligadas a la mercadotecnia empresarial. De la combinación de aspectos sociales (intereses, valoraciones, percepciones, etcétera) con otros económicos que no están al margen de los planteamientos estratégicos y de la consideración del territorio como agente básico en la determinación de los procesos de desarrollo, pueden generarse metodologías nuevas que acaben con el estancamiento citado y con la falta de orientación de los modelos teóricos, y sobre todo de método, para evaluar en qué medida el desarrollo de los territorios procede o se relaciona con los recursos patrimoniales. 
Convertir en productos los recursos culturales sigue siendo un objetivo prioritario de las políticas patrimoniales; que dicho producto sea gestionado de forma sostenible y equilibrada son dos cuestiones ya comúnmente aceptadas, que además sea un producto visible y de calidad son los retos a los que debe dar respuesta la gestión patrimonial en los próximos años.

\section{Bibliografía}

AA.VV. (2006): Andalucía: Segundo informe de desarrollo territorial, Sevilla, Universidad de Sevilla.

ALBERTOS, J.M.; CARAVACA, I.; MÉNDEZ, R. y SÁNCHEZ, J.L. (2004): «Desarrollo territorial y procesos de innovación socioeconómica en sistemas productivos locales» en ALONSO-APARICIO-SÁNCHEZ: Recursos Territoriales y Geografía de la Innovación Industrial en España, pp. 15-60, Salamanca,Ediciones Universidad.

BORDIEU, P. (1997): Capital cultural, escuela y espacio social, Siglo Veintiuno, México.

BRUNDTLAND,G.H. (1989): Nuestro futuro común, Madrid, Alianza.

CARAVACA, I.-GONZÁLEZ, G.-SILVA, R. (2004) «Análisis del entorno en sistemas productivos locales de Andalucía», en ALONSO, J.L.-APARICIO, J.-SÁNCHEZ, J.L. (Eds) Recursos territoriales y geografía de la innovación industrial en España. Salamanca, Ediciones de la Universidad de Salamanca, pp. 63-80.

CARAVACA BARROSO, I.-GONZÁLEZ ROMERO, G.-SILVA PÉREZ, R. (2005) «Innovación, redes, recursos patrimoniales y desarrollo territorial, en EURE, Revista Latinoamericana de Estudios Urbano-Regionales $\mathrm{n}^{\circ}$ 94, pp. 5-24

CEPAL (1991): El desarrollo sustentable: transformación productiva, equidad y medio ambiente, Santiago de Chile, CEPAL-ONU.

CREVOISIER, O. (2001): «L'approchepar les milieux innovateurs: etat des liéux et perspectives», Revue d'Economie Règionale et Urbaine No 1, pp. 135-166.

DELFOSSE, C. (1997): «Noms de pays et produits de terroir: enjeux des dénominations géographiques», en L'Espace Géographique, no 26, pp. 222-230.

FERNÁNDEZ SALINAS, V. (2003): «Patrimonio y desarrollo. ¿Realidad o deseo?», en JORNADAS de Patrimonio y Desarrollo, pp. 29-61, Asociación de geógrafos Españoles y Consejería de Cultura de la Junta de Andalucía, Úbeda-Baeza.

FERNÁNDEZ SALINAS, V. y ROMERO MORAGAS, C. (2008): «El patrimonio local y el proceso globalizador. Amenazas y oportunidades. Tendencias futuras en la gestión local del patrimonio», pp. 17-29.

FERRAO, J. (1996): «Educacao, sociedades cognitivas e regiones inteligentes: una articulacao promissora» Cultura, identidades y territorios. Inforgeo, 11, pp. 97-104.

GRAHAM, B.; ASHWORTH, G.J. y TUNBRIDGE, J.E. (2000): A Geography of Heritage: Power, Culture, Economy, Arnold, Londres.

GDRU (en prensa): «Recursos patrimoniales y organización territorial: el caso de Andalucía», Ciudad y Territorio. Estudios Territoriales.

GÓMEZ DE LA IGLESIA, R. (2001): Cultura, desarrollo y territorio, Xabide Gestión, Cultura y Comunicación, Vitoria.

GREENFIELD, J. (1996): The Return of Cultural Treasures, Cambridge University Press, Cambridge (Reino Unido).

GREFF, X. (1990): La valeur économique du patrimoine. La demande et l'offre de monuments, Anthropos, París.

GUÍA para la puesta en valor del patrimonio del mundo rural (2000), Sevilla, Consejería de Agricultura y Pesca, Junta de Andalucía.

ILBERY, B. y. KNEAFSEY, M. (1998): «Product and place. Promoting quality products and services in the lagging rural regions of the European Union», en European Urban and Regional Studies, $\mathrm{n}^{\circ} 5$, pp. 329-341. 
JIMÉNEZ HERRERO,L. M. (1982): Economía y medio ambiente, Madrid, CEOTMA.

JIMÉNEZ LATORRE, F. Y RAMS RAMOS, C. (2002): «Crecimiento económico en un contexto de desarrollo sostenible», en Información Comercial Española, $\mathrm{n}^{\circ}$ 800, pp. 47-64.

MOSE, I. y WEIXLBAUMER, N. (2003): «Großschutzgebiete als Motoren einer nachhaltigen Regionalentwicklung? Erfahrungen mit ausgewählten Schutzgebieten in Europa», en HAMMER (ed.): Großschutzgebiete. Instrumente nachhaltiger, Munich, Entwicklung, pp. 35-95.

MOYANO, E. (2001): «El concepto de capital social y su utilidad para el análisis de las dinámicas de desarrollo «Revista Fomento Social, $\mathrm{n}^{\circ}$ 56, pp. 35-63

PÉREZ DE ARMIÑO, A. (dir., 2002): Diccionario de Acción Humanitaria y Coorperación al Desarrollo, Barcelona, Icaria.

PETITFORD, L. (1996): «Changing Conceptions of Security in the Third World», Third World Quarterly, vol. 17, $\mathrm{n}^{\circ}$ 2, pp. 289-306.

ORTEGA VALCÁRCEL, J. (1998): «El Patrimonio Territorial como recurso cultural y económico» Ciudades, 4. Territorio y Patrimonio, Valladolid, Instituto de Urbanística de la Universidad de Valladolid

RALLET, A. (1996): Gobalization el délocalisation des activités:l'impact des technologies de l'information et de la communication sur l'emploi, IRIS_TS, Université de Paris-Dauphine, París.

ROMERO MORAGAS, C. (2001): «Ciudad, cultura y turismo: calidad y autenticidad», PH, Boletín del Instituto del Patrimonio Histórico, $\mathrm{n}^{\circ}$ 9, pp. 100-109.

SILVA, R.-DEL MORAL, L. (2005) «Dinámicas socio-económicas y alternativas de desarrollo territorial. El caso de la zona regable del Bajo Guadalquivir», en Boletín de la Asociación de Geógrafos Españoles, n 40, pp. 223-244.

SILVA, R. y otros (2007) «Los Parques Naturales de Sierra Morena: Apoyo institucional y dinámica socio-económica reciente». La Geografía en la frontera de los conocimientos. Actas del XX Congreso Nacional de Geografía. [En dvd] Sevilla, Junta de Andalucía-Universidad Pablo de Olavide.

SILVA PÉREZ, R. (2008): «Hacia una valoración patrimonial de la agricultura», en Scripta Nova. Vol. XII n ${ }^{\circ}$ 273. http://www.ub.edu/geocrit/nova.htm

TICKNER, J.A., (1995): «re-visioning Security» en BOOTH, K.-SMITH, S. (edits.), International Relations Theory Today, Cambridge, Polity Press, pp. 175-197.

VÁZQUEZ BARQUERO, A. (1993): Política económica local, Pirámide, Madrid.

VAZQUEZ BARQUERO, A. (2005): Las nuevas fuerzas del desarrollo, Barcelona, Antoni Bosch.

VÁZQUEZ BARQUERO, A. (1999): Desarrollo, redes e innovación, Pirámide, Madrid.

VELTZ, P. (1998): Mundialización, ciudades y territorios, Barcelona, Ariel.

VOTH, A. (2003): «Aufwertung regionaltypischer Produkte in Europa durch geographische Herkunftsbezeichnungen», en Europa Regional, ${ }^{\circ} 11$, pp. 2-11.

ZOIDO, F. (2001): Informe de desarrollo territorial de Andalucía, Sevilla, Fundación Sevillana de Electricidad-Universidad de Sevilla-La General Caja de Granada. 